Cahiers $d u$ MONDE RUSSE

\section{Cahiers du monde russe}

Russie - Empire russe - Union soviétique et États indépendants

$43 / 4 \mid 2002$

Intellectuels et intelligentsia

\title{
Jean-Louis Van Regemorter, L'insurrection paysanne de la région de Tambov
}

\section{Alain Blum}

\section{OpenEdition}

\section{Journals}

Édition électronique

URL : https://journals.openedition.org/monderusse/4023

DOI : $10.4000 /$ monderusse.4023

ISSN : $1777-5388$

Éditeur

Éditions de l'EHESS

\section{Édition imprimée}

Date de publication : 30 décembre 2002

Pagination : 712-713

ISBN : 2-7132-1796-2

ISSN : $1252-6576$

Référence électronique

Alain Blum, « Jean-Louis Van Regemorter, L'insurrection paysanne de la région de Tambov », Cahiers du monde russe [En ligne], 43/4 | 2002, mis en ligne le 17 juin 2009, consulté le 03 septembre 2022 URL : http://journals.openedition.org/monderusse/4023; DOI : https://doi.org/10.4000/monderusse. 4023

Ce document a été généré automatiquement le 3 septembre 2022.

Tous droits réservés 


\title{
Jean-Louis Van Regemorter, L'insurrection paysanne de la région de Tambov
}

\author{
Alain Blum
}

\section{RÉFÉRENCE}

Jean-Louis VAN REGEMORTER, L'insurrection paysanne de la région de Tambov. Luttes agraires et ordre bolchevik, 1919-1921. Documents traduits du russe et précédés par « Le concept d'une révolution paysanne unique de 1902 à 1922 ». Édition annotée par Régis Gayraud. Cœuvres-et-Valsery (02600), Ressouvenances, 2000, 212 p.

1 Ce recueil de documents est issu du travail du regretté Jean-Louis Van Regemorter, décédé en novembre 1999, à partir de l'important recueil de documents publié à Tambov en 1994, intitulé Krest'janskoe vosstanie v Tambovskoj gubernii v 1919-1921 gg. "Antonovščina». Dokumenty $i$ materialy (Tambov, 1994). Il est composé d'une introduction de Van Regemorter, suivi d'un court texte de Régis Gayraud, qui a pris en charge cette édition, puis de la traduction de 26 documents issus du recueil publié à Tambov. L'introduction permet de replacer cette révolte paysanne, qui fut l'une des plus marquantes des années qui suivirent la révolution, dans le contexte de l'histoire paysanne russe et des événements révolutionnaires, ainsi que de la relation conflictuelle et complexe entre bolcheviks et paysans dès 1918. Les documents sélectionnés permettent de rendre accessibles au lecteur français les matériaux d'une nouvelle histoire de l'URSS qui puise largement dans les documents administratifs, ordres, proclamations et rapports transmis le long de l'échelle hiérarchique, décrivant avec force détails situation, conflits, position et actions de répression. Bien entendu, le recueil russe reste indispensable pour les spécialistes, et cette édition française ne permet pas de plonger dans toute la complexité et la violence de cet épisode caractéristique de la période. Mais, malgré tout, la palette de documents présentés reflète bien l'ensemble : proclamations hostiles aux koulaks et cherchant à convaincre 
le paysan russe sans beaucoup de chances de succès, rapports d'une extrême précision mais aussi d'une froide détermination de Vladimir Antonov-Ovseenko, l'un des principaux responsables ayant assuré la répression contre cette révolte. Un texte de ce type montre à quel point le rapport administratif est une source riche, tant par ce qu'il exprime que par les indications qu'il donne, notamment sur les ordres de commandements, dont la forme témoigne des rapports de force et des représentations des responsables éloignés des lieux de l'action, de leur incompréhension autant que des formes de délégations qu'ils élaborent, etc.

On regrettera cependant, dans ce recueil, le ton de la seconde introduction de Régis Gayraud, qui tranche avec l'approche complexe, nuancée et historienne de Jean-Louis Van Regemorter. R. Gayraud, au contraire, assène un jugement définitif de l'action bolchevique, simplifiant ce que fournissent ces documents et ne laissant pas au lecteur la liberté de comprendre, mais lui imposant ces simplifications qui font tant de mal à l'histoire soviétique. La violence bolchevique est évidente, elle est complexe et tenter de la cerner ne passe pas par une vision qui explique tout à partir du mal absolu que constitue la révolution russe, comme le fait cet auteur. Il est aussi dommage que les commentaires de bas de page qu'il a rajoutés mêlent précisions et jugements (soulignons d'ailleurs que l'un des principaux protagonistes de ces violences, AntonovOvseenko, n'est pas décédé en 1939, mais a été fusillé en février 1938). On est loin de la pensée toute en nuances de Van Regemorter.

Quoi qu'il en soit, on a dans ce petit ouvrage un condensé particulièrement appréciable des documents qui constituent aujourd'hui la base du travail historien. Il constitue une source appréciable tant pour les enseignants et étudiants qui travaillent sur cette période, que pour un public plus large, désireux de mieux comprendre les sources qui renouvellent aujourd'hui l'histoire soviétique. 